\title{
A construção de um saber sobre as cidades nos escritos de Manoel de Araújo Porto-alegre*
}

\author{
Priscilla Peixoto \\ Arquiteta e Urbanista, professora da Universidade do Grande Rio \\ (Unigranrio) e doutoranda no Programa de Pós-graduação em \\ Urbanismo (Prourb) da FAU/UFRJ, membro do grupo de pesquisa \\ Laboratório de Estudos Urbanos (LeU - Prourb/UFRJ), Av. Reitor \\ Pedro Calmon, 550, Prédio da FAU/Reitoria, $5^{\circ}$ andar, sala 521 \\ Cidade Universitária, Rio de Janeiro, RJ, priscillapeixoto@gmail.com
}

\begin{abstract}
Resumo
O presente trabalho parte de um conjunto de documentos de meados do século XIX que testemunham a ação de Manoel de Araújo Porto-alegre na crítica e na construção da Rua Leopoldina, apresentando as atuações deste intelectual com relação ao papel dos arquitetos na construção das cidades. Assim, busca-se tanto explorar uma faceta pouco conhecida de Porto-alegre, como também situa-lo no pensamento urbanístico de seu tempo.
\end{abstract}

Palavras-chave: pré-urbanismo, Rio de Janeiro, Manoel de Araújo Porto-alegre.

* O presente trabalho se beneficiou de recursos das bolsas de mestrado do CNPq e da FAPERJ.

1 Optamos pela grafia "Porto-alegre" por se tratar da maneira como o próprio autor passou a assinar seu nome durante os anos que produziu os textos aqui tratados. Como apontado por seus biógrafos, esse sobrenome foi uma construção do autor que por batismo se chamava Manuel José de Araújo.

2 Com relação à atenção de Porto-alegre às questões urbanas podemos citar os seguintes trabalhos: PEREIRA, Margareth A. S. Rio de Janeiro: l'éphémère et la perennité - Histoire de la ville au XIXème siècle. 1988. Tese (Doutorado em História) - École des Hautes Études en Sciences Sociales, Paris, 1988; MACEDO, Francisco Riopardense de. Arquitetura no Brasil e ...continua próxima página.. anoel de Araújo Porto-alegre ${ }^{1}$ [1806-1879] foi um destacado personagem no quadro intelectual do Império brasileiro em meados do século XIX. Por esse motivo, sua vida e obra vêm sendo objeto de inúmeros estudos que tratam, sobretudo, de seu papel preponderante no meio artístico do século XIX e de suas incursões como literato e membro do Instituto Histórico e Geográfico Brasileiro (IHGB). No entanto, apenas recentemente sua atenção às questões urbanas vem despertando interesse de estudiosos do tema².

Para o estudo desse aspecto pouco conhecido de sua fortuna crítica, dois conjuntos de documentos são particularmente significativos: aqueles que testemunham a ação de Manuel de Araújo Portoalegre na crítica e na construção da Rua Leopoldina (atual Rua Imperatriz Leopoldina) - proposta de Grandjean de Montigny ${ }^{3}$ para embelezar e ligar o acesso principal da Academia Imperial de Belas Artes ao Rossio (atual Praça Tiradentes) -, seguidos por aqueles que apresentam a sua atuação ao tomar parte no debate da inserção dos arquitetos nas obras públicas. Buscaremos demonstrar como esses dois conjuntos estão intimamente ligados e denotam uma mesma preocupação em considerar as cidades como objeto de ação e reflexão dos arquitetos formados pela antiga Academia Imperial de Belas Artes.

Esta questão mostra-se particularmente interessante, pois durante boa parte do período em que Porto-alegre viveu no Brasil e atuou junto à Academia ${ }^{4}$, devido a uma série de desentendimentos nos planos institucional e político, suas propostas ficaram circunscritas ao campo literário. As fontes aqui abordadas e, consequentemente, o período contemplado apresentam, portanto, um momento excepcional da ação de Porto-alegre. Trata-se de ações (críticas e projetuais) encampadas entre 1850 e 1855, nas quais ele tem a possibilidade de atuar diretamente na forma física da cidade.

Para desenvolver o presente trabalho, toma-se como referencial teórico a noção de "préurbanismo", conforme cunhada por Françoise Choay. Os "pré-urbanistas" constituem um grupo 
. continuação da nota 2 ..

Araújo Porto Alegre. Porto Alegre: UFRGS, 1984; SALGUEIRO, Heliana Angotti. A comédia urbana: de Daumier a Porto-alegre. São Paulo: MAAB-FAAP, 2003; SQUEFF, Letícia. O Brasil nas letras de um pintor: Manoel de Araújo Porto-alegre (1806-1879). Campinas: Unicamp, 2004; PEIXOTO, Priscilla A. Os escritos de Manoel de Araújo Porto-alegre sobre cidades [1844-1853]: Temporalidades e sedimentações. 2013. Dissertação (Mestrado em Urbanismo). Rio de Janeiro: PROURB/UFRJ, 2013.

3 Auguste Henri Victor Grandjean de Montigny, "arquiteto francês de muita importância no Brasil, foi membro da chamada Missão Artística Francesa que chegou ao Rio de Janeiro em 1816 com o objetivo de criar a Escola Real de Ciências, Artes e Ofícios. Na Academia Grandjean era professor da aula de arquitetura e durante mais de 30 anos será o único professor dessa matéria". Cf. PEREIRA, Margareth A. S. Biografia de Auguste Henri Victor Grandjean de Montigny. In: Cronologia do pensamento urbanístico. Disponível em: <https://goo.gl/RVLyQW> Acesso em: 20 nov. 2016.

4 Porto-alegre foi aluno da Academia Imperial de Belas Artes entre 1827 e 1831 . Seis anos mais tarde, retorna a Academia como professor de "Pintura histórica", ocupando a cadeira de seu mestre, Jean-Baptiste Debret até 1849 . Entre 1854 e 1858 , volta mais uma vez à instituição para exercer o cargo de diretor

5 Certeau entende que a história é uma prática, o que nos permite pensar o trabalho do historiador como uma construção processual. Ele assinala também a importância de se perceber como escrita da história é condicionada pelo lugar social que o indivíduo ocupa. Centrado especificamente na produção historiográfica, soma-se a ela os limites impostos pelas fontes que se tem acesso e pelo o campo teórico que o historiador utiliza para interpretá-las. Cf. CERTEAU. Michel de. A escrita da história. Rio de Janeiro: Forense Universitária, ...continua próxima página.. de generalistas que se dedicaram à descrição e/ou problematização dos fenômenos de urbanização antes de ter sido constituído um campo disciplinar próprio, o urbanismo.

Nosso referencial teórico busca valorizar também a atenção aos discursos literários que contribuíram para a formação do urbanismo no século XX. Este último, enfocado tanto por Choay como também por Jean-Pierre Gaudin. Choay justifica a necessidade de estudar os "textos instauradores da disciplina" como um modo de remontar os debates iniciais (o contexto de enunciação) dos modelos do urbanismo disseminados no século XX. Gaudin, por sua vez, desloca esse olhar retrospectivo de Choay para o estudo não apenas dos textos inaugurais, mas também da produção textual de grupos de técnicos e de agentes do estado que ressignificaram o urbanismo em suas práticas e ações quotidianas.

Esses referenciais nos levam a tomar por hipótese que o estudo dos escritos de Porto-alegre pode trazer contribuições para se pensar a cultura urbanística, conforme ela pôde ser praticada no Brasil do século XIX.

O referencial metodológico que baliza nossa pesquisa se beneficia tanto da noção de "operação historiográfica" de Michel de Certeau (1974) ${ }^{5}$ quanto da noção de "biografia intelectual", formulada por François Dosse $(2005)^{6}$. Ambos nos levam a trabalhar a interpretação das fontes aqui apresentadas considerando não apenas as questões por ela tematizadas, mas também suas condições de enunciação e seu caráter processual.

Este trabalho organiza-se em quatro partes. As duas primeiras - "A crítica de Porto-alegre à abertura da Rua Leopoldina" e "Construção da Rua Leopoldina e proposta para a Rua do Cano: a crítica na forma de projeto" - ressaltam aspectos da crítica de Porto-alegre em relação ao projeto de Grandjean de Montigny. As duas últimas partes - "Em meio à crítica, a valorização do saber arquitetônico" e "Valorização social dos arquitetos: entre a cultura administrativa e a reformulação pedagógica da academia" - discorrem sobre uma aparente contradição, o envolvimento de Porto-alegre na construção do projeto de Grandjean.

\section{A crítica de Porto-alegre à abertura da Rua Leopoldina}

Conforme apresentado anteriormente, nosso ponto de partida é um debate em que Porto-alegre se envolveu no ano de 1850. Tratava-se da polêmica que ele instaurou em torno do projeto de construção da Rua Leopoldina, idealizado pelo arquiteto Grandjean de Montigny. Este projeto criava um novo desenho para as edificações da rua e um largo em semicírculo junto à escola (PUC, 1979). Contudo, para sua execução, demandava a demolição de algumas construções existentes. Este projeto fazia parte de uma série de propostas de Grandjean, que vinham se acumulando desde a década de 1820, para interligar diferentes instituições do Império ${ }^{7}$. Dessas grandes propostas de remodelação e embelezamento do Rio de Janeiro na primeira metade do século XIX, a Rua Leopoldina era uma das poucas que havia saído do papel e somente seria totalmente concluída após sua morte em 1850, apesar de idealizada em 1836.

Em 1850, com a obra já em curso, Porto-alegre escreveu um artigo para a revista Guanabara em que criticava a proposta de Grandjean (PORTOALEGRE, 1850, n² 2, p. 76). Nesta revista, que o próprio Porto-alegre editava, ele publicou o texto "Academia de Belas Artes - exposição pública do ano de 1829", onde escreve:

Não há utilidade alguma para as artes e para o ensino a abertura da rua Leopoldina ao Rossio: é melhor que esse dinheiro seja empregado na construção de uma boa sala no terreno que está junto da Academia, cuja sala iluminada convenientemente possa servir para a aula do nue, durante o ano, para a exposição pública [...] (PORTO-ALEGRE, 1850, n² 2, p. 76)

Porto-alegre questionava a necessidade de investimento público na construção da rua projetada por Grandjean que visava unicamente o embelezamento do acesso à Academia, em detrimento da ampliação da escola.

No entanto, suas propostas ficariam mais explicitas apenas em um segundo escrito abordando novamente a Rua Leopoldina. Trata-se de um artigo publicado na revista Guanabara como parte da série "Algumas ideias sobre a arte a e indústria no Império 
... continuação da nota 5 ...

1982. e CERTEAU. Michel de. A operação histórica. In: LE GOFF, Jacques. NORA, Pierre. (org.). História: novos problemas. Rio de Janeiro: Francisco Alves, 2011.

6 Dosse nos ajuda a pensar a biografia como gênero de escrita da história que possibilita uma espécie de jogo entre várias escalas de análise. Não se enxerga o indivíduo biografado apartado de sua rede de sociabilidade ou sem estar condicionado por certos limites sociais e/ou culturais, mas mantém sobre ele um olhar atendo às especificidades dos gestos individuais. Mais especificamente em relação à "biografia intelectual", aquela que se volta sobretudo a vida de filósofos e homens de letras, Dosse assinala a importância de estabelecer uma leitura transversal entre sua vida e a produção intelectual. Cf. DOSSE, François. La pari biographique: écrire une vie. Paris: La Découverte, 2005.

7 Dois livros são referências no levantamento das obras de Grandjean para o Rio de Janeiro: PUC-Rio. Uma cidade em questão: Grandjean de Montigny e o Rio de Janeiro. Rio de Janeiro: PUC-Rio, Funarte e Fundação Roberto Marinho, 1979 e TELLES, Angela. Grandjean de Montigny: da arquitetura revolucionária à civilização nos trópicos. Rio de Janeiro: ed. Arquivo Nacional, 2008. Deve-se salientar também o projeto "Gosto Neoclássico: Grandjean de Montigny e a arquitetura no Brasil (18161850)" dirigido por Ana Pessoa do Santos (FCRB) e Margareth da Silva Pereira (UFRJ) na catalogação e construção de uma base de dados das obras do arquiteto. do Brasil". Neste artigo Porto-alegre também criticava a maneira como as edificações propostas para a rua pareciam subjugadas à intenção de evidenciar a fachada da Academia, sem se preocupar com o conforto daqueles que a utilizavam. Apontava também para a estreiteza da rua proposta, que parecia não levar em consideração a circulação de veículos que segundo ele, rapidamente se tornaria uma nova demanda daquela área (PORTO-ALEGRE, 1850, n³, pp.108-115).

Esse conjunto de escritos demonstra de fato a atenção do intelectual Porto-alegre aos debates sobre a cidade em meados do século XIX. Contudo, no modo como ele engendra sua crítica a Grandjean observa-se também a posição lateral que ele ocupava junto às obras propostas pela Academia. Nesse período, Porto-alegre estava afastado desta instituição e desempenhava apenas as atividades de editor na revista Guanabara e de professor substituto na Escola Militar.

Essa crítica tornava-se mais contundente não apenas pela posição marginal de Porto-alegre junto à Academia. Deve-se sublinhar também que ela se acentuou após a aposentadoria de Felix-Émile Taunay e a morte do próprio Grandjean, últimos representantes da Missão Artística Francesa que ainda atuavam na instituição. Esse aspecto deve ser salientado porque a partir desse momento é possível pensar que Porto-alegre buscasse retomar os debates sobre a arquitetura e a cidade. Esta tarefa ele começara a desempenhar no período em que seus aliados políticos estiveram no poder, mas a havia perdido desde que os conservadores se restabeleceram (PEIXOTO, 2013, pp.103-110).

\section{Construção da Rua Leopoldina e proposta para a Rua do Cano: a crítica na forma de projeto}

Alguns anos após a realização dessas críticas, quando Porto-alegre volta a ter reconhecimento institucional no Império e assume a direção da Academia Imperial de Belas Artes, é particularmente curioso notar que ele passa a ser também o novo responsável pela execução das obras da Rua Leopoldina, mais especificamente da abertura do quarteirão próximo ao Rossio.
Dois documentos pertencentes hoje ao museu $D$. João VI - as correspondências oficiais de Porto-alegre ao Ministro de Negócios do Império, Luiz Pedreira do Coutto Ferraz -, justamente nos mostram a tarefa de Porto-alegre durante esse novo período. No ofício de 30 de junho de 1854 ele apresenta as negociações necessárias à segunda etapa de obras, a abertura da porção da rua junto ao Rossio:

IImo. e Exmo. Sr. - Sua Majestade o Imperador me ordenou que eu tratasse da continuação da abertura da rua Leopoldina até a Praça da Constituição, e em consequência disto, fui falar ao Dr. Francisco de Salles Torres Homem, procurador de Francisco Alvares Machado, proprietário da casa fronteira à rua e situada na referida praça. O Dr. Salles me disse que, em conseqüência da sua posição de empregado do Tesouro, Ihe parecia que não deveria figurar em semelhante negócio, apesar de que a lei (...) não (..) [o excluir]. Fui [também] à Estrela falar a Francisco Alvares Machado, e este me disse que [não há] nenhum obstáculo (...) de sua parte para a conclusão deste negócio, quer (...) [pela proposta] de trocar o seu prédio por um próprio nacional (...) [e] repor ao Tesouro o excedente da avaliação, (...) [conforme a lei de] permutação [autoriza], (...) [quer pela proposta de] ceder pelo meio da desapropriação, segundo a outra lei (...). (...) Como nada tenho encontrado na secretaria desta Academia a respeito deste negocio, nem tradições positivas sobre o estado em que o deixou (...) [o Sr.] Taunay, ex-diretor, rogo a V. Exa. o obséquio de me dar (...) suas ordens a fim de que se cumpra a vontade de Sua Majestade, o Imperador, que está firme em mandar executar a abertura desta nova porção da rua Leopoldina, como por duas vezes já me fez a honra de dizer. Da abertura desta rua resultará uma vantagem na negociação da compra dos prédios da rua Lampadosa, porque um dos proprietários aí tem uma casa que ficará com duas frentes (...), uma vez que o Governo Ihe ceda o resto do terreno que fica fora do alinhamento; pois (...) já fiz (...) [com que esse proprietário visse] o quanto avultaria o valor do seu prédio se ele (...) [se mostrasse] razoável, (...) [visto] que todas as propriedades daquele quarteirão subirão a preços fabulosos logo que se concluir a nova Rua Imperial, sobre a rua do Cano, (...) e pela novidade e beleza das novas construções que ali se edificarão segundo os planos que estou fazendo a pedido da llustríssima Câmara Municipal. - (...) [Em] vista do exposto, V. 
8 Museu D. João VI. Correspondência da Academia Imperial de Belas Artes (recebidas). Notação: 6126 .

${ }^{9}$ Com relação à atuação de Porto-alegre como vereador, a análise das atas das sessões do Legislativo municipal permite afirmar que ele foi candidato a vereador substituto no pleito de 1853. No entanto, apenas foi convocado a assumir o cargo em junho. A partir dessa data, verifica-se que Porto-alegre compareceu regularmente às sessões da câmara até julho do mesmo ano. (Cf. Sessões do legislativo municipal, Arquivo geral da Cidade do Rio de Janeiro. Documentação sob a notação: 17.2.23). A partir daí e até janeiro de 1854, Porto-alegre passa a figurar como ausente, com falta justificada. Acreditamos que nesse período Porto-alegre encontrava-se enfermo, conforme mencionou em seus apontamentos autobiográficos (cf. PORTO-ALEGRE, Manoel de Araújo. Apontamentos biográficos. In: Porto-alegre: uma autobiografia inédita de Araújo Porto-alegre. Rio de Janeiro: Jornal do Comércio, 19 mai. 1822). Durante o restante do ano de 1854, não foi possível verificar a presença de Porto-alegre na Câmara a partir das atas do legislativo municipal, atualmente um documento em condição muito frágil. No entanto, atesta sua presença ainda como vereador da câmara, uma memória de projeto para a abertura da Rua do Cano, datada de 22 de dezembro de 1854, e a assinada por Porto-alegre ("Apresentação do vereador Araújo Porto-alegre da sua proposta para abertura da Rua do Cano ligando-a ao Largo do Paço, em sessão da Câmara dos Vereadores de 10 de dezembro de 1854", Arquivo Nacional, notação: IJJ10-21).

10 Arquivo Nacional. Apresentação do vereador Araújo Porto-alegre da sua proposta para abertura da Rua do Cano (atual sete de setembro) ligando-a ao Largo do Paço, em sessão da Câmara dos Vereadores de 10 de dezembro de 1854. Códice: IJJ10-21.
Exa. ficará na certeza de que (...) não (...) [me poupo em] vencer dificuldades e de que estou pronto para apressar um negócio, no qual devemos todos ter o maior empenho, pois é da vontade de Sua Majestade o Imperador. - Deus guarde a V. Exa. por muitos anos. Palácio da Academia das Belas Artes em 30 de junho de 1854. - IImo. e Exmo. Sr. Ministro e Secretário de Estado dos Negócios do Império. Manoel de Araujo Porto-Alegre. Diretor ${ }^{\text {. }}$.

Nessa correspondência, apesar da aparente contradição de levar à realização um projeto que ele havia duramente criticado, deve-se salientar como Porto-alegre buscava justamente encampar esse antigo projeto junto àqueles com os quais ele mesmo estava envolvido na Câmara Municipal.

Eleito para o cargo de vereador suplente em 1853, apesar de pouco assíduo às sessões, Portoalegre envolveu-se em alguns projetos dessa casa entre 1853 e 1854 e, também, cumpriu papel de parecerista em relação a propostas dos demais colegas vereadores ${ }^{9}$.

Pela citação transcrita anteriormente pode-se pensar que no momento em que foi chamado a completar o projeto proposto por Grandjean, Porto-alegre vislumbrasse a possibilidade de articulá-lo com outras propostas que havia realizado para a cidade, entre as quais se destaca um projeto para a Rua Cano, atual Rua Sete de Setembro ${ }^{10}$.

Em seus apontamentos autobiográficos ${ }^{11}$ Portoalegre relacionou uma série de atividades junto à Câmara Municipal, tais como o projeto para a região do Mangue (de São Diogo), a revisão do Código de Posturas para a cidade e um projeto para o Campo de Santana. No entanto, a proposta para a Rua do Cano é um dos poucos projetos arquitetônicos de Porto-alegre a que podemos ter acesso em nossos dias. O documento consta apenas de um memorial descritivo encaminhado pelos vereadores e encontrase atualmente no Arquivo Nacional12

O projeto de abertura da Rua do Cano é uma contraproposta à intenção da Câmara de ligar, em linha reta, o Rossio ao Largo do Paço, atual Praça $\mathrm{XV}$ de Novembro. Ao que tudo indica, tratava-se de uma das antigas propostas de Grandjean para a cidade (de 1825), que voltava agora a ser discutida na Câmara onde se considerava sua construção.
Porto-alegre buscava persuadir os demais vereadores a desistir dessa antiga proposta, alegava que se ela fosse realizada se destruiria "uma grande quantidade de edifícios, inclusive uma boa parte do templo de S. Francisco de Paula" e se "faria uma despesa sem utilidade nem beleza"13.

Em seu projeto, Porto-alegre oferecia aos habitantes do Rio de Janeiro uma rua ampla, iluminada a gás, bem calçada, com recolhimento de águas pluviais e capacidade de se tornar uma importante "via de comunicação" para a cidade, ladeada por galerias e lojas térreas. Em todas as questões apresentadas, Porto-alegre se opunha claramente à proposta de Grandjean de Montigny para a Rua Leopoldina, respondendo a quase todos os pontos que havia explicitado na crítica publicada anos antes na revista Guanabara.

Em relação às propostas de Grandjean, a Rua do Cano diferenciava-se também por afirmar outra tendência em relação à construção das cidades, pois não enfocava e articulava palácios e edifícios do governo, ao contrário, inclinava-se para a construção de uma urbanidade burguesa, cuja arquitetura passava a enquadrar cada vez mais o citadino e seus modos de vida. Ou seja, Porto-alegre tornava seu projeto uma espécie de manifesto contra a maneira pela qual Grandjean havia pensado os melhoramentos urbanos no Rio de Janeiro ${ }^{14}$.

No entanto, mesmo deslocando o interesse para este outro projeto, pode-se dizer que as dúvidas sobre as motivações de levar à frente a abertura da Rua Leopoldina, encampada por Porto-alegre como diretor da Academia, ainda suscitam atenção. Dito de outro modo, uma pergunta persiste: por que apoiar uma construção cujo projeto tanto havia criticado?

\section{Em meio à crítica, a valorização do saber arquitetônico}

Para responder a essa questão, pode-se dizer que Porto-alegre desenhava para si outras intenções, para além da oposição às propostas e às ações de Grandjean, em que pesam a busca por um trabalho mais articulado entre as obras realizadas pela Câmara Municipal, a expertise técnica dos engenheiros da Escola Militar e o conhecimento espacial e compositivo dos arquitetos. 
11 Existem duas versões desses apontamentos biográficos, uma manuscrita disponível em: Instituto Histórico e Geográfico Brasileiro. PORTO-ALEGRE, Manoel de Araújo. Autobiografia (do próprio punho). Notação: ARQ. 1.4.29; e outra publicada em: PORTO-ALEGRE, Manoel de Araújo. Porto-alegre: uma autobiografia inédita de Araújo Porto-alegre. Rio de Janeiro: Jornal do Comércio, 19 mai. 1922

12 lbid.

13 lbid.

14 Destacamos que essa visão negativa frente às contribuições de Grandjean são marcas do discurso de Porto-alegre que nesta época buscava afirmar suas próprias posições. Sobre às contribuições de Grandjean para o pensamento urbanístico no Brasil ver: PEREIRA. Margareth S. P. O Rio de Janeiro no século XIX - cenários, formas e virtudes de uma cidade-capital. In: PINHEIRO, Augusto Ivan de Freitas. Rio de Janeiro: cinco séculos de transformações urbanas. Rio de Janeiro: Casa da Palavra, 2010; e também: PEIXOTO, Priscilla. O Caminho do Aterrado e o pensamento urbanístico no Brasil (1825-1853). In: Revista do Arquivo Geral da Cidade do Rio de Janeiro, n. 10-11. Rio de Janeiro: AGCRJ, 2016.

15 Com relação à iniciativa de Taunay e Grandjean de engajar artistas da Academia nas obras do governo, ver: DIAS, Elaine. Félix-Émile Taunay e a recepção da tradição clássica na Academia Imperial de Belas-Artes (1834-1851). In: Rotunda. Campinas: CEPAB-IA-UNICAMP, n. 4, 2006.

16 Desde os tempos em que o Brasil ainda era uma colônia portuguesa, a Escola Militar formava oficiais aptos a zelar pelo território e pelo patrimônio dos colonos. Dessas obrigações decorriam tanto lições relativas às atividades bélicas - manobras militares e o manejo das armas - quanto lições relativas às demarcações de fronteiras e à construção de fortificações e vias de comunicação. Dessa forma, a Academia Militar encampava tanto disciplinas militarizadas quanto disci...continua próxima página..
É justamente a proposta para a Rua do Cano - sua crítica na forma de projeto - que melhor nos dá pistas para compreender a questão. Nela, Portoalegre claramente articulava tanto preocupações estéticas para a composição da perspectiva da rua, quanto outras relativas à higiene como, por exemplo, a necessidade do encanamento das águas. Também estavam presentes preocupações de ordem socioeconômica, relativas à responsabilidade do uso dos recursos do orçamento da municipalidade. Com relação a esse último aspecto, a proposta de Porto-alegre propunha edificações simples, que pudessem servir de modelo para as construções futuras, bem como um partido regular que garantisse um orçamento preciso e possibilitasse a redução nos custos, caso fosse construída mais de uma unidade.

Ao entrelaçar essas diversas formas de ação, Portoalegre não apenas lançava um olhar complexo em relação ao perfil de profissionais que passariam a se ocupar das questões urbanas, mas também indicava as competências necessárias aos arquitetos formados pela Academia Imperial de Belas Artes. Tratava-se de uma prática que os ligava cada vez mais a uma fina atenção à vida em cidades.

Aqui, Porto-alegre parece revisitar também sua trajetória, trazendo para o debate público sua experiência do período em que viveu na França (1831-1837). Em Paris ele pôde acompanhar tanto uma série de transformações da cidade como a construção da Rue de Rivoli, assim como conviver com François Debret, arquiteto francês que nessa época havia desempenhado importantes papéis, tais como: arquiteto da cidade de Paris (architecte de la ville de Paris) nos trabalhos extramuros (1815) e membro do Institut de France desde 1825.

No Brasil, percebe-se nos escritos de Porto-alegre desde o fim da década de 1840, a valorização da especificidade de sua formação como arquiteto, entendendo-a como uma importante voz na tarefa de elaborar cenários futuros para a cidade.

Essa questão é explicitada, sobretudo, no artigo já citado "Algumas ideias sobre as Belas Artes e a Indústria no Império do Brasil", no qual Porto-alegre apontava que "ainda não chegou a época de se acreditar que o arquiteto é tão útil à civilização de um país, como o médico à saúde do indivíduo" (PORTO-ALEGRE, 1850, n³, p.114). Como essa citação começava a insinuar, instaurar o diálogo entre o ensino arquitetônico e os debates urbanísticos no Brasil, nesse meado de século XIX, esbarrava também em outra questão, talvez mais pragmática: a necessidade de se criar nichos de atuação para os arquitetos formados pela Academia.

A partir da produção desse texto e apesar de haver rivalizado com Taunay e Grandjean durante toda a sua carreira (PEIXOTO, 2016, p.108), Portoalegre parecia claramente apoiar a causa desses acadêmicos na tentativa de inserir os artistas e os demais profissionais formados na Academia Imperial de Belas Artes nas obras do governo ${ }^{15}$.

Possivelmente, essa questão tenha se agudizado para o próprio Porto-alegre, à medida em que se aproximou dos engenheiros formados pela Escola Militar. No Brasil, esse grupo possuía uma tradição na concepção de obras públicas que remontava ao período colonial ${ }^{16}$. Portanto, possuía também um reconhecimento social do seu saber diferente dos arquitetos que, com estatuto de artistas, ainda precisavam conquistar e legitimar um espaço relativamente novo nas repartições do governo.

Após a morte de Grandjean, sobretudo no período em que Porto-alegre assume a direção da Academia, além de não conseguir garantir a seus alunos atuação nas obras públicas, a instituição enfrentava outras dificuldades como a diminuição de verbas, a redução da quantidade de alunos inscritos e a perda da preferência pela prática da arquitetura. Segundo Helena Cunha de Uzeda (2002), no período de 1834 a 1854:

A procura pelo curso de arquitetura não chegou perto de representar $63 \%$ dos alunos matriculados como ocorrera em 1830, época em que 14 alunos frequentavam o ateliê de Montigny. Durante esses vinte anos, a média de alunos de arquitetura em relação ao universo de estudantes acadêmicos manteve-se em apenas 8\%; entre 1846 e 1854 uma média de seis alunos frequentavam anualmente o curso de arquitetura, demonstrando que este não avançara quase nas três décadas após sua implantação. (UZEDA, 2002, p. 50)

Essa autora considera que o esvaziamento do curso de arquitetura na Academia desenhava-se desde a década de 1830. Além disso, Uzeda aponta que 
continuação da nota 16 plinas similares ao que hoje conhecemos por engenharia civil. Cf. TELLES, Pedro Carlos da Silva. História da Engenharia no Brasil. Rio de Janeiro: Clavero, 1994

17 Museu D. João VI, op. cit. a diminuição da procura pelo curso justamente poderia ter como motivação "a crescente valorização dos estudos civis dentro da prestigiada Academia Imperial Militar" (UZEDA, 2002, p. 50).

Acredita-se que por ter circulado tanto entre engenheiros militares do Brasil quanto entre arquitetos de diferentes nacionalidades, os termos desse descompasso de representatividade, bem como as especificidades do saber arquitetônico para a construção das cidades, tenham se tornado mais evidentes para Porto-alegre. Assim, observa-se que uma das pautas que o levou a se tornar diretor da instituição foi requalificar o prestígio dos arquitetos formados por ela e trabalhar sua maior inserção profissional.

Por esse motivo, mesmo não concordando com a orientação projetual, talvez Porto-alegre encampasse a proposta de Grandjean para a Rua Leopoldina. Tratava-se da necessidade de afirmar a ação dos arquitetos, enquanto grupo, para além das rivalidades pessoais. Corrobora a nossa hipótese, o fato de Porto-alegre, logo de início, envolver também na sua condução o professor de arquitetura da Academia Job Justino de Alcântara ${ }^{17}$.

O que podemos constatar é que no momento em que se tornou diretor da Academia e que passou a assumir a responsabilidade pela finalização da proposta de Grandjean, entre outras funções, sua preocupação com relação ao papel dos arquitetos nas obras de utilidade pública ia passando de uma especulação crítica a sucessivas ações.

\section{Valorização social dos arquitetos: en- tre a cultura administrativa e a refor- mulação pedagógica da Academia}

Nesse processo de luta pela valorização social da figura dos arquitetos, é importante notar a especificidade de própria trajetória de Porto-alegre, em especial do papel que passou a desempenhar junto à administração municipal.

Há longa data, sobretudo ao produzir um periódico jocoso chamado A lanterna mágica (1844-1845), Portoalegre criticava a maneira como as obras públicas da cidade vinham sendo conduzidas, em especial a pouca atenção dada à qualificação das propostas. Constatava que para a realização de qualquer empreendimento, mesmo aqueles voltados para o interesse geral, essas eram colocadas em um segundo plano e conduzidas com o objetivo de favorecer relações de compadrio, prestígio individual e lucro.

Na referida revista, desferia contra os vereadores uma série de acusações envoltas em uma espécie de joguete teatral. $\mathrm{Na}$ "cena $\mathrm{VI}$ " de sua Lanterna, por exemplo, os dois personagens principais, Laverno e Belchior, encenavam a decisão de participar das eleições para vereador e explicavam as atividades (lícitas e ilícitas) que se travam na Câmara Municipal.

[...] [Belchior:] - Pois [o] que se pode lucrar da Ilustríssima [Câmara Municipal] para te apresentares candidato nas eleições? Tu, que não dás passo sem ver bagaço! [...]

[...] [Laverno:] - Eis aí como cada vez te mostras mais simplório, pateta; pois se a coisa não pingasse havia de haver tanta cabala entre mais de setenta e seis farejadores que se disputam em chapas de diversas redações [?] havia de haver tanta fome de ser vereador em alguns dos finados [...]? Repara, [...] Belchior, que ali há coisa que cheira a toucinho. Sobre aquela mesa em que se disputam os destinos do município tancham-se ruas, alargam-se praias, enxugam-se pântanos, prolongam-se pontes, aterram-se paus, compram-se terrenos, levantamse muros, abatem-se casas, repartem-se gorjetas, beneficiam-se compadres, arranjam-se afilhados, [...] [arrematam-se] prédios, calçam-se ruas, ajustam-se empreitadas, atiçam-se morrões de candeeiros, estreiam-se obras de Santa Engrácia, fazem-se estradas, cobram-se multas, litigiam-se posses, e por fim traçam-se Programas para festas carnavais, e só por se não admitir um mais pomposo, [...] ficou tudo no fundo da botija, e nós privados de ver transplantada a [...] Veneza para este Rio de Janeiro.

[...] [Belchior:]-Alhos, bugalhos, carvalhos e malhos... que diabo de ladainha é essa tão comprida! Onde foste desencavar tudo isso? E o que tem tanta coisa com os lucros que são sempre nossa principal mira.

[...] [Laverno:] - Tem muita coisa; eu já tenho descoberto o fio [...] [da meada], e até mesmo no afã de certos sujeitinhos [que] bem [...] [deixam passar] o chorume dos tais empregos que tu chamas grátis: olha eu poderei não sair vereador, porque enfim são tantos! Mas hei de fazer tudo o que puder para galgar essa honra; e quando menos farei meu 
18 Ata da 2a Sessão Pública da Academia das Belas Artes, em 27 de setembro de 1855 - Presidência do Diretor. In: Museu D. João VI. Atas da Academia Imperial de Belas Artes (sessões da Presidência do diretor). Notações: 6151, 6152 e 6163. 'debut' para a futura legislativa [...] (PORTO-ALEGRE, $\left.1844, n^{\circ} 6\right)$

Como citado anteriormente, cerca de oito anos após a publicação dessas críticas, era Porto-alegre quem passava a fazer parte da Câmara e, não só tinha de lidar com a questão a partir de outras bases (agora não mais jocosas), como também se defrontava com a necessidade de formar uma cultura de valorização de profissionais do urbano.

Deste modo, pode-se pensar que sua própria ação era imbuída por um caráter pedagógico. Ao se tornar propositor de projetos para a Câmara e ao buscar reconhecimento para se tornar parecerista de propostas de seus colegas vereadores, Porto-alegre talvez estivesse tentando construir uma cultura de valorização do arquiteto a partir de suas ações. Assim, o próprio Porto-alegre aventurava-se em desempenhar esse novo perfil, misto de político, engenheiro e arquiteto.

No entanto, à medida em que ele se tornou também diretor da Academia, a mesma preocupação ganhou outras tonalidades, tornou-se necessário atualizar os próprios artistas com relação à especificidade de seu saber. Nesse contexto, Porto-alegre propõe uma série de temas para a pauta de uma revista da Academia em que se sobressai a necessidade de formar "o gosto" dos governantes e o papel desempenhado pelos artistas-arquitetos no desenvolvimento de obras de "utilidade pública". Na transcrição da sessão em que esses temas são propostos, podemos ler:

2. ${ }^{\circ}$ - Donde procede o mau gosto, e mesmo a indiferença que temos tido até hoje para com a arquitetura, quais as razões porque os exemplares de Mr. Grandjean não frutificaram, e o que convém fazer em favor desta arte para ter um maior e seguro desenvolvimento?

\section{[...]}

$11 .^{\circ}$ - No momento em que os altos poderes do Estado decretarem a edificação de um palácio para o nosso Imperador, qual será o local mais conveniente, mais belo e mais econômico para este monumento nacional?

12. ${ }^{\circ}$ - O Estado, a moralidade pública, e o indivíduo lucrariam mais se todas as repartições públicas estivessem em um só edifício, ou convém separar os diferentes ramos da administração? Qual seria o melhor local, na primeira hipótese, para esta edificação, e que plano geral conviria adotar no desenvolvimento do seu todo para haver nele rápida correspondência e economia de tempo para o cidadão, de despesa para o Estado, e de ordem para a alta administração?

13. - Que meios pode empregar já o Governo para enraizar o gosto das belas artes no Rio de Janeiro, e torná-lo em utilidade pública?

\section{[...]}

$18^{\circ}$ - As nossas construções urbanas estão em harmonia com o nosso clima e vida doméstica? Mudarão elas na sua disposição interior depois da extinção da escravatura, e no caso contrário quais serão as introduções úteis que se devem adotar desde já para que se tornem mais belas, cômodas e sanitárias? E o que convém ao legislador decretar para este fim?

$20 .^{\circ}$ - O que tem mais concorrido para o atraso da arquitetura, as leis do nosso país, e educação dos nossos homens de Estado, ou a falta do gosto nos particulares? ${ }^{18}$

Essas teses para debate claramente explicitam o projeto de Porto-alegre de aproximar os arquitetos formados pela Academia aos debates urbanísticos, bem como Ihes ampliar a forma de atuação junto às obras públicas. Contudo, pouco se sabe em relação à recepção dessas teses. Certamente, sua fortuna crítica do século XX é mais extensa do que aquela que circulou junto aos contemporâneos de Portoalegre. De fato, a revista $\mathrm{O}$ artista, não passou de uma proposta. Possivelmente, seu insucesso se deveu às animosidades que sempre o acompanharam dentro da Academia. Como a historiografia é farta em mostrar, seu gênio e suas rivalidades na instituição prejudicavam o desenvolvimento de suas propostas para as artes e para o ensino.

Apesar do silêncio dos contemporâneos de Portoalegre diante de seu projeto de construir a figura do arquiteto como intelectual envolvido nos debates urbanos, pode-se dizer que houve alguma difusão de suas ideias. É necessário lembrar que uma série de intelectuais foram então formados diante de sua postura pública frente às questões urbanas. 
19 Rafael Mendes de CarvaIho [1817-1870] nasceu em Laguna (SC), mudou-se para - Rio de Janeiro por volta de 1839-1840. Colaborou com Porto-alegre nas obras de reforma do Teatro São Pedro de Alcântara em 1841. Matriculou-se na Escola de Arquitetos-Medidores em 1841 e recebeu prêmio de viagem à Itália em 1845. Cf. Enciclopédia Itaú Cultural. Disponível em: <http://enciclopedia.itaucultural.org.br/ pessoa24118/rafael-mendes-de-carvalho>. Acesso em: 26 nov. 2016.
Dos menos conhecidos, como Rafael Mendes de Carvalho $^{19}$, que após trabalhar com Porto-alegre na revista A lanterna mágica seguiu o curso na efêmera Escola de Arquitetos Medidores - instituição que ensaiou instaurar junto aos engenheiros uma prática especialmente civil e ligada à problemática específica das cidades -, àqueles mais reconhecidos como o grande cronista da vida urbana na segunda metade século XIX, Joaquim Manuel de Macedo. Antes de trabalhar com Porto-alegre na produção da revista Guanabara, Macedo já possuía uma produção atenta aos costumes, mas limitada a paisagem campestre. Assim, mesmo sem realizar todas as suas ambições - tudo o que conseguiu formular enquanto discurso -, as preocupações de Porto-alegre configuraram uma cultura que cada vez mais inseriu as cidades no centro dos debates dos intelectuais do século XIX.

\section{Conclusão}

Buscando trazer contribuições para o estudo do pensamento urbanístico do século XIX, o presente artigo dedicou-se à interpretação de um conjunto de documentos que testemunham a ação de Portoalegre com relação às questões urbanísticas.

Nosso ponto de partida foi um artigo em que ele apresenta argumentos contra uma proposta de Grandjean de Montigny para a Rua Leopoldina para se demonstrar como, no decorrer de cinco anos, suas próprias posições frente a esse projeto foram sendo moduladas.

Pela crítica a uma postura excessivamente balizada pelo olhar compositivo da arquitetura da cidade, Porto-alegre chama a atenção para uma certa transdisciplinaridade necessária a sua construção - a higiene, as técnicas construtivas, as questões socioeconômicas e também o embelezamento -, bem como, a ação de ajuizamento que essas iniciativas implicam.

Entretanto, a constatação de uma aparente ambiguidade inscrita no envolvimento de Porto-alegre na construção da referida rua, poucos anos depois de suas críticas, também nos ajudou a perceber outra questão: seu engajamento na valorização da figura dos arquitetos nas obras de utilidade pública.

Neste ponto, buscamos demonstrar que ela envolvia três direções: (1) conscientizar a municipalidade da importância desse papel; (2) construir um novo nicho de atuação para os alunos formados pela Academia Imperial de Belas Artes, em franco desprestígio naqueles anos; e (3) estruturar em termos pedagógicos a atenção às questões urbanas no interior dessa instituição. Concluímos por constatar que sua própria trajetória como vereador e diretor pareciam encarnar essas lutas, levando-as para além do esforço de formulação da questão no campo literário.

Assim, a despeito do pouco reconhecimento das contribuições de Porto-alegre para a formação de urbanístico no Brasil, o presente artigo buscou salientar seu esforço em ressignificar a cultura citadina no século XIX, sobretudo ao fazer um voto de confiança a sua valorização. Igualmente destacamos seu papel como formador. Ou seja, acreditamos que sua maior contribuição tenha sido trabalhar para o florescimento de um olhar mais atento e delicado aos temas citadinos nas gerações que se seguiram, assim como se esforçar para que uma tradição iniciada por Grandjean não fosse perdida, realizando-os sem reducionismos e sem se abster de uma ação crítica.

\section{Referências bibliográficas}

CERTEAU. Michel. A escrita da história. Rio de Janeiro: Forense Universitária, 1982

A operação histórica. In: LE GOFF, J. NORA, P. (org.). História: novos problemas. Rio de Janeiro: Francisco Alves, 2011

DIAS, Elaine. Félix-Émile Taunay e a recepção da tradição clássica na Academia Imperial de Belas-Artes (18341851). In: Rotunda. Campinas: Cepab-IA-Unicamp, n. 4, 2006

Paisagem e academia: Félix-Émile Taunay e o Brasil (1824-1851). Campinas: Ed. Unicamp, 2009.

DOSSE, François. La pari biographique: écrire une vie. Paris: La Découverte, 2005

LOBO, Hélio. Manoel de Araújo Porto-alegre. Rio de Janeiro: Empresa Editora ABC Ltda., 1938.

LOPES, Hélio. A divisão das águas: contribuição ao estudo das revistas românticas Minerva Brasiliense (18431845) e Guanabara (1849-1856). São Paulo: Conselho Estadual de Artes e Ciências Humanas, 1978.

MACEDO, Francisco Riopardense de. Arquitetura no Brasil e Araújo Porto Alegre. Porto Alegre: UFRGS/ CREA-RS, 1984

PEIXOTO, Priscilla. O Caminho do Aterrado e o pensamento urbanístico no Brasil (1825-1853). In: Revista do Arquivo Geral da Cidade do Rio de Janeiro, $\mathrm{n}^{\circ}$ 10-11. Rio de Janeiro: AGCRJ, 2016. 
Os escritos de Manoel de Araújo Porto-alegre sobre cidades [1844-1853]: Temporalidades e sedimentações. 2013. Dissertação (Mestrado em Urbanismo). Rio de Janeiro: PROURB/UFRJ, 2013.

PEREIRA, Margareth A. S. Rio de Janeiro: I'éphémère et la perennité - Histoire de la ville au XIXème siècle. 1988. Tese (Doutorado em História) - École des Hautes Études en Sciences Sociales, Paris, 1988

O Rio de Janeiro no século XIX: cenários, formas e virtudes de uma cidade-capital. In: PINHEIRO, Augusto Ivan de Freitas. Rio de Janeiro: cinco séculos de transformações urbanas. Rio de Janeiro: Casa da Palavra, 2010

Biografia de Auguste Henri Victor Grandjean de Montigny In: Cronologia do pensamento urbanístico, 2003. Disponível em: <https://goo.gl/RVLyQW>. Acesso em: 20 nov. 2016.

PORTO-ALEGRE, Manoel de Araújo. Academia das Belas Artes: exposição pública do ano de 1829. In: Guanabara: revista artística, cientifica e literária. Rio de Janeiro: [s.ed.], tomo I, n² 2 , janeiro, 1850.

Algumas Ideias sobre as belas artes e a industria no Império do Brasil. In: Guanabara: revista artística, cientifica e literária. Rio de Janeiro: [s.ed.], tomo I, n³, fevereiro, 1850 .

. Algumas Ideias sobre as belas artes e a industria no Império do Brasil ( $2^{\circ}$ artigo). In: Guanabara: revista artística, cientifica e literária. Rio de Janeiro: [s.ed.], tomo I, n4, março, 1850.

Notícias Diversas. In: Guanabara. Rio de Janeiro: Tipografia Paula Brito, tomo 1, nº 7, 1851.

Novo sistema de calçadas In: Guanabara. Rio de Janeiro: Tipografia Paula Brito, tomo 1, nº 10, 1851.

Porto-alegre: uma autobiografia inédita de Araújo Porto-alegre. Rio de Janeiro: Jornal do Comércio, 19 mai. 1922.

PUC-Rio. Uma cidade em questão: Grandjean de Montigny e o Rio de Janeiro. Rio de Janeiro: PUC-Rio, Funarte e Fundação Roberto Marinho, 1979.

ROCHA-PEIXOTO, Gustavo. Arquitetos do Brasil Imperial: a obra arquitetônica dos primeiros alunos da Academia Imperial de Belas Artes. 2004. Tese (Doutorado em História). PPGHIS-UFRJ, Rio de Janeiro, 2004.

SALGUEIRO, Heliana Angotti. A comédia urbana: de Daumier a Porto-alegre. São Paulo: MAAB-FAAP, 2003.

SQUEFF, Letícia. O Brasil nas letras de um pintor. Manoel de Araújo Porto-alegre (1806-1879). Campinas: Ed. Unicamp, 2004

TELLES, Angela. Grandjean de Montigny: da arquitetura revolucionária à civilização nos trópicos. Rio de Janeiro: ed. Arquivo Nacional, 2008

TELLES, Pedro Carlos da Silva. História da engenharia no Brasil. Rio de Janeiro: Clavero, 1994.

TRAJANO FILHO, Francisco Sales. Tentativas de enraizamento: arquitetura brasileira e formação nacional. 2010. Tese (Doutorado em Teoria e História da Arquitetura e do Urbanismo). EESC-USP, 2010.
UZEDA, Helena Cunha de 0 ensino de arquitetura na Academia de Belas Artes: 1826-1889. In: PEREIRA, Sonia Gomes (org.). 185 anos de Escola de Belas Artes. Rio de Janeiro: Programa de Pós-Graduação em Artes Visuais, Escola de Belas Artes, 2002

\section{Fontes documentais}

A lanterna mágica: periódico plástico e filosófico. Rio de Janeiro: Typographia Francesa, 1844. n 1

A lanterna mágica: periódico plástico e filosófico. Rio de Janeiro: Typographia de Berthe \& Haring, 1844. $n^{\circ} 2$.

A lanterna mágica: periódico plástico e filosófico. Rio de Janeiro: [s. ed.], 1844. $n^{\circ} 3$

A lanterna mágica: periódico plástico e filosófico. Rio de Janeiro: Typographia Autral, 1844-1845. n 4-10.

A lanterna mágica: periódico plástico e filosófico. Rio de Janeiro: Typographia Barroso e comp., [s.d.]. nº 11.

Guanabara: revista artística, científica e literária. Rio de Janeiro: Typographia Guanabarense de L. A. F. de Menezes, 1849-1856. $n^{\circ} 1-6$

Guanabara: revista artística, científica e literária. Rio de Janeiro: Typographia da Empreza Dous de Dezembro de Paula Brito, 1849-1856. n 7-13.

Instituto Histórico e Geográfico Brasileiro. PORTO-ALEGRE, Manoel de Araújo. Autobiografia (do próprio punho). Notação: ARQ. 1.4.29.

Arquivo Geral da Cidade do Rio de Janeiro. PORTO - ALEGRE, Manuel de Araújo. Melhoramentos da cidade do Rio de Janeiro. Proposta e pareceres dos vereadores Francisco de Paula Mattos e Manoel de Araujo Porto Alegre, 1853. Localização: índice textual volume 3.

Arquivo Geral da Cidade do Rio de Janeiro. Atas das sessões do legislativo municipal. Notações: 17.2.23 e 17.2.24. Sessões: 18 jun. 1853: 25 jun. 1853: 02 jul. 1853; 06 jul. 1853; 09 jul. 1853; 16 jul. 1853; 20 jul. 1853; 26 jul. 1853; 30 jul. 1853; 06 ago. 1853; 13 ago. 1853; 20 ago. 1853; 27 ago. 1853, 03 set. 1853; 10 set. 1853; 17 set. 1853; 01 out. 1853: 08 out. 1853; 15 out. 1853; 22 out. 1853 29 out. 1853; 05 nov. 1853; 19 nov. 1853; 26 nov. 1853; 03 dez. 1853; 10 dez. 1853; 17 dez. 1853; 21 jan. 1854.

Arquivo Nacional. Apresentação do vereador Araújo Porto-alegre da sua proposta para abertura da Rua do Cano (atual sete de setembro) ligando-a ao Largo do Paço, em sessão da Câmara dos Vereadores de 10 de dezembro de 1854. Códice: IJJ10-21.

Arquivo Nacional. [Memorial descritivo do projeto da Rua do Cano encaminhado a Câmara Municipal em 22 de dezembro de 1854]. Códice IE7 43.

Museu D. João VI. Atas da Academia Imperial de Belas Artes (sessões da Presidência do diretor). Notações: 6151,6152 e 6163

Museu D. João VI. Correspondência da Academia Im perial de Belas Artes (recebidas). Notação: 6126. 